\title{
Study on a New Classification of Causes which Generate Deffects of Injection Molding Products
}

\author{
LILIANA LUCA*, MINODORA MARIA PASARE \\ University Constántin Brancusi of Targu-jiu, Faculty of Engineering, 30 Eroilor Str., 210163, Targu-Jiu, Romania
}

\begin{abstract}
In this paper we present a study that was conducted to determine the classification of causes that generate defects in products obtained by injection of plastic material. A classification of the causes of defects is made by applying a quality management tool - the Ishikawa diagram. The causes are grouped into $M$ categories, for defects generated by the design process and for defects generated by the injection process. A new model of the diagram is created by composing two fish skeletons (model $4 M+5 M$ ). At the end of the paper, the importance of the Ishikawa diagram is shown.
\end{abstract}

Keywords: plastic parts, defects, causes, Ishikawa diagram

The plastics appeared in the first half of the nineteenth century and experienced a permanent evolution. Plastics have excellent properties and are widely used in a variety of engineering applications (textiles, leather, footwear, textiles, packaging, consumer goods, optics, sanitary and electrical, glass, table, automotive, aerospace, chemical industry, agriculture, etc.).

At present there is a large worldwide development of the packaging industry made of plastics. Injection molding is used to produce thin-walled plastic plastic parts for a wide variety of applications, one of the most common being plastic plastic housings. These housings are used in a variety of products. These housings are used in a variety of products. Other thin-walled products are receptacle type. Injection molding is also used in the manufacture of dailyuse articles, such as toothbrushes or toys. Also, some medical devices, including valves and syringes, and are manufactured using injection molding as well.

The injection process depends on a large number of factors, which can lead to a large range of nonconformities. Each nonconformity (defect) can be determined by several specific causes. Once the causes are known, appropriate measures are taken to eliminate them or to diminish the effect on the final product. The problem of defects in plastic products obtained through injection molding has been studied quite a lot in recent years, due to the development of plastic products manufacturing. Concerns in this field have been present both in researchers from universities and research institutes as well as in specialists working in companies manufacturing plastics products. At present, companies are interested in raising the quality of manufactured products and by targeting all processes and activities to the customer and optimizing them to deliver long-term profit. In order to know and analyze the causes that determine the variation of the characteristics of a product or process, classical and modern tools of quality management can be applied. In the field of quality, they are used quality management tools in order to substantiate quality improvement decisions.

Specialty literature offers many papers on defects in plastic products and on improving the quality of these products. In the paper [1] there are 10 defects of the injection molding process including remediation solutions: Flow Lines, Sink Marks, Vacuum Voids, Surface Delamination, Weld Lines, Short Shots, Warping, Burn Marks, Jetting and Flash. Another classification of defects of parts obtained by injection molding is given in [2], where Texas Plastic Technologies presets a number of 15 defects. The defects studied were related to the manufacturing process and did not include those resulting from the poor design of the products. In [3] there are presented 11 main defects of the injection molding process and the prevention methods. Another paper, [4], presents the causes for a number of 13 defects of injection molded parts.

There have been several studies on the quality of plastic products. In 5 , the issue of applying the $5 S$ tool, in quality management to a plastic industry company, is addressed to build a stronger ethics for the workman and engineer. $A$ study based on the six sigma quality philosophy is presented in [6] and refers to quality improvementfor defectmitigation in the Plastic Injection Molding Industry. In paper [7] there is a surface defect in plastic parts, called the ghost marks, which is characterized by a local change of glare and the causes of this defect are demonstrated. The authors of the paper [8] investigate the Kriging surrogate modeling method in establishing the relationship between the parameters of the injection molding process and the sink defect on the surface of a plastic part. An optimization method for minimizing the defect is also discussed.

Another study on the quality of plastic parts parts is presented in [9]. The paper presents the Taguchi method, which is used to create a system for optimizing process parameters for quality improvement. The paper [10] is a study which shows the correlation of the quality of the mixture of three polymers with the process parameters in order to obtain quality products. In paper [11] is presented the study of the parameters of the optical qualities process for injection molded plastic lenses. An experimental analysis of the surface defects generation in the injection molding process is given in [12]. In this study, the authors investigated the conditions in which surface defects appear.

In [13] a study is presented on the influence of melt and process parameters on the quality and occurence of partial defects in water-assisted injection molded tubes. In the paper are shown the process parameters such as melt temperature, water hold time and water volume flow rate as well as melt parameters such as shear viscosity, which have an influence on the formation of part defects. Article [14] shows inherent defects of injection molded products and their special processes. In this article, some common defects, which are caused by material properties, and the mechanism of the defects occur are introduced. In the

\footnotetext{
*email: lylyanaluca@yahoo.com
} 
paper [15] there are the defects of the products obtained by forging and the actions that can be taken to reduce these defects. A study on quality defects due to plasticity viscosity material in powder injection molding filling process is given in the paper [16]. The formation and shape change of the high viscosity areas are studied. A recent study [17] relates to the M-Integral based failure description on elasto-plastic materials with defects under biaxial loading. A non-dimensional II-parameter is defined, and a novel failure criterion based on the II-parameter is proposed to assess the multi-defected average. The paper [18] presents the behaviour of elasto-plastic materials with damaged microstructure.

Several studies using the Ishikawa Diagram (Quality Management Tool) for different quality issues, but not for the quality of injection molded parts, are given in the literature. The Ishikawa Diagram is defined as a graphic representation that schematically illustrates the relationship between a specific result and its causes. The studied effect or negative problem is the fish head and the potential causes and sub-causes define the fish bone structure [19]. The diagram was originally designed with the division of causes into different categories of $M$ ( man, machine, method, material, etc.), was subsequently applied in different fields of activity and so the diagram was extended to other categories of causes. Currently the Ishikawa diagram has multiple uses both in the field of product manufacturing for different industries and in the field of services, education, public administration, commerce, etc.).
In the paper [20] is presented the investigation of shrinkage defect in castings by Ishikawa diagram and Pareto chart, and in [21] is given the cause and effect diagram Ishikawa as a useful tool in the design economic analyzes. In the paper [22], the authors present aspects of the use of the Ishikawa diagram for the classification of causes that generate weld defects. A new model of Ishikawa diagram is given in [23]. The paper presents the results of a study on the use of the Ishikawa diagram in the analysis of causes that generate errors in the precision assessment of the precision parts in the machine construction field. In [24] it is presented a study on the cause-effect diagram applied to analyzing the quality of public order services. The paper [25] presents a study on the application of quality management in the development of projects, respectively the quality planning.

From the study of several specialized papers published in this area, some of which are presented above, it can be said that the problem of product quality is a matter of great importance for the management of companies that want to profit from selling the products in a competitive market.

\section{Experimental part}

Potential causes of defects of plastic products obtained by injection molding

The study presented in this paper relates to the identification and classification of potential causes that generate defects in plastic injection products. Following the study of the papers presented in introduction as well as

Table 1

MAIN AND SECONDARY CAUSES OF DEFECTS

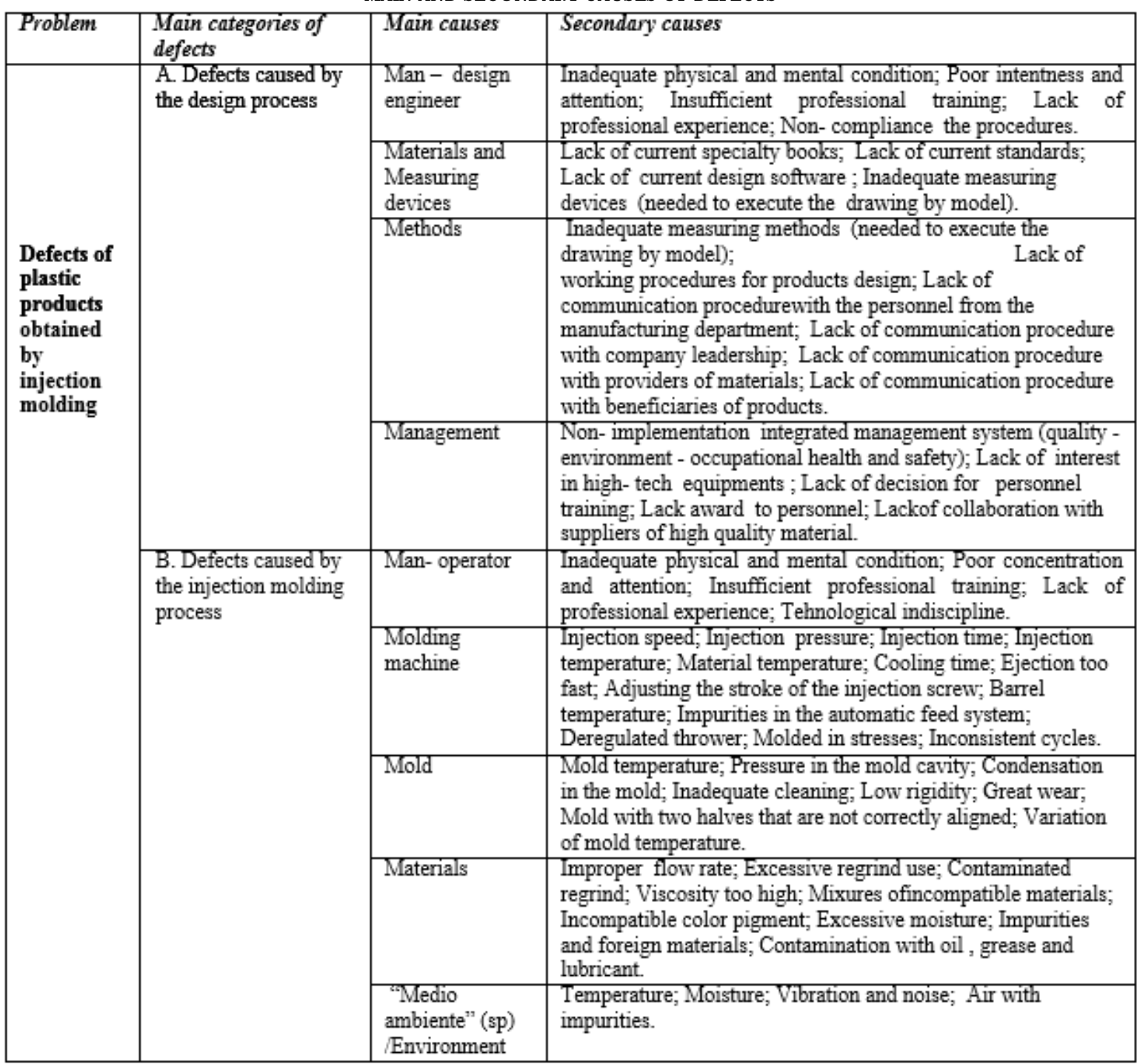


on the results obtained after a Brainstorming meeting with specialists in the field of plastics, the list of 21 defects is presented:Flow Lines, Sink Marks (small craters), Vacuum Voids (Bubbles), Surface delamination, Weld Lines, Short Shots, Warping, Burn Marks, Jetting on the surface of the piece, Flash, Black Specks or Streaks, Blister, Brittle, Contamination, Cracking / Crazing, Shrinkage, Warpage, Silver Streak, Partial Discoloration, Variation of the mass of the same type of parts injected consecutively, Deforming the part during and after throwing.

From the analysis of the causes of the defects, it results that the defects are generated by errors that occur during two important processes: the injection molding process and the process of designing the parts. In this paper we propose a new classification of the causes that generate the defects of plastic products. Classification of the causes is based on the methodology of the Ishikawa diagram, so that an Ishikawa diagram is finally made. The causes are divided into two main categories: specific causes of the product design process and causes specific to the injection molding process. For each of these two categories of causes the main causes (categories of $M$ ) and then the secondary causes were determined. This new rlaccifiration ic nrocontod in tahlo 1

\section{Results and discussions}

Determining the Ishikawa chart is done in accordance with the quality management methodology. In this paper were used the steps proposed by Dale in [25], namely the following:

-It is defined very clearly the effect of the problem considered;

-It is written the effect in the right and it is drawn a line from right to left;

- It is checked if each team member has understood well the problem;

-They are determined the main categories of causes which are the main branches of the diagram;

-It is organized a Brainstorming session to determine possible secondary causes;

-It is organized another brainstorming session in order to discuss in detail the causes and to determine those who have the major degree of probability for producing the studied effect;

-They are traced and recorded the appropriate subbranches.

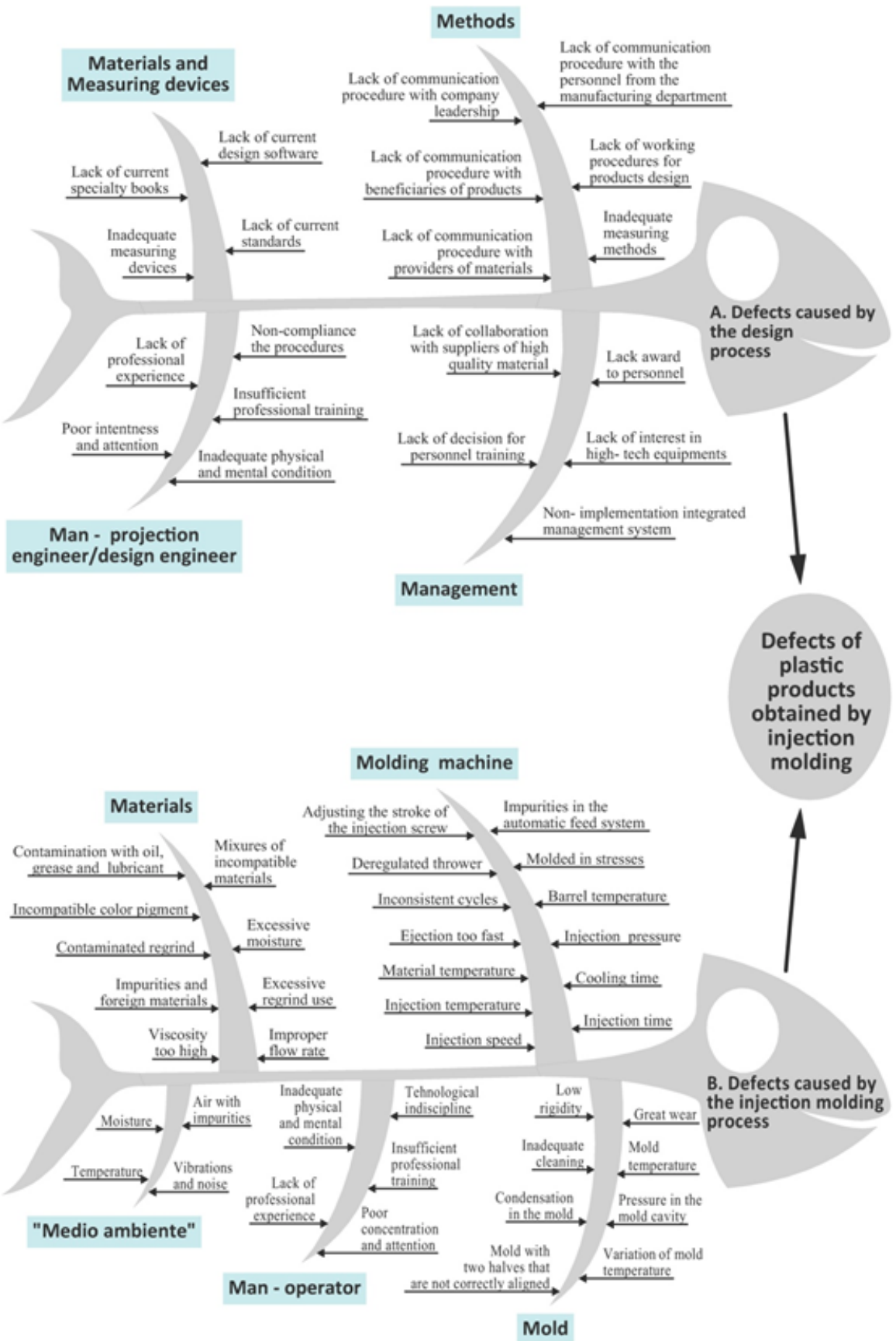

Fig. 1. Ishikawa diagram - model $4 M+5 M$ 
The problem considered was defined as: Defects of plastic products obtained by injection molding. This problem will be the fish head of the Ishikawa diagram (fishbone diagram).

Based on the causes classification presented in table 1, a new model of the Ishikawa diagram is being constructed. The new model is composed of 2 fish skeletons, a fish skeleton for the design process and a fish skeleton for the injection molding process. In the fish skeleton corresponding to the product design process, the causes are ordered into 4 categories of $M$ (Man-projection engineer, Materials and Measuring devices, Methods, Management). The second fish skeleton, which corresponds to the injection molding process, has five categories of $M$ (Man-operator, Molding Machine, Mold, Materials, Medio Ambiente-Environement). A new form was obtained for the diagram that in this paper is called: the Ishikawa model $4 M+5 M$. The resulting diagram is shown in figure 1.

A brief analysis of the diagram shows that the precision of plastic products is mainly due to: the professional training of designers and engineers, the quality of the materials used, the precision of the machines, the working regime projected, the working regime applied in the manufacturing, the quality of the mold, the management team's attitude towards the quality problem, the characteristics of the working environment, the methods applied by the designers, the endowment with the equipment and performance software of the workshop. Once known, causes can be solved to reduce defects in the desired direction.

It is also noted that most causes are directly or indirectly related to staff and available machines or devices. It can be said that the personnel with technical expertise and skills in industrial design and manufacturing as well as the endowment with machines for performing technologies represent the solution for the success of the companies that manufacture plastic products.

This diagram can be used by the organization's management to focus on improving to a greater extent the design process and manufacturing process. The created diagram helps organizations with activities in the field of plastics products manufacturing in determining the best measures and actions to reduce and eliminate the causes of defects.

\section{Conclusions}

The Ishikawa diagram determined in the paper allows the hierarchy of possible causes that cause defects in plastic injection products. Based on the literature review and a Brainstorming session, a list of 21 defects and the causes that determine them is made. It was taken into account that product defects are the result of the activities carried out during two main processes: the design process and the injection molding process. Because the Ishikawa diagram has the advantage of allowing a clear definition of the problem studied, the authors have used the specific methodology of this diagram and identified the potential causes that cause defects in molded products. The diagram obtained consists of two fish skeletons, namely a fish skeleton for the design process and a fish skeleton for the injection molding process. All causes were ordered by " $\mathrm{M}$ " categories. Thus, a new model of the Ishkawa Diagram consisting of the composition of two fish skeletons, named in the paper, $4 M+5 M$ was drawn up.

In a particular organization, the Ishkawa diagram can be used later for study to choose the best solutions for defect reduction. A case study can be made at a profile company that calculates the share of parts with different defects by category of causes, what costs involve the possible remedies for each cause and then suggests the optimal solution. Particular attention should be given to designers and engineers, as it is known that experienced staff is the mostimportant part of any process. Experienced staff offer creative solutions and great ingenuity, so you can make the bestcombination of hardware and software.

Companies should be interested in best practices in performance management. Good practice models that apply quality management tools should also be used by companies that produce plastic products. For big companies that make large-scale plastic products, mistakes that can cause irrecoverable rebuttal products or low-quality products should be prevented.

\section{References}

1. SUKIE WHITEHALL, Top-10 Injection Molding Defects And How To Fix Them, 2017, published in https://www.creativemechanisms.com/ blog/what-cause-injection-molding-defects-and-how-to-fix-them

2. *** Plastics Molding\& Manufacturing/Defects, 2017, published in https://en.wikibooks.org/wiki/Plastics_Molding_\%26_Manufacturing/ Defects

3. OLIVER KNACK, 11 Injection molding defects and how to prevent them, 2015, published in https://www.intouch-quality.com/blog/ injection-molding-defects-and-how-to-prevent

4. INCLAZAN, T., Tehnologia prelucrarii materialelor plastic si composite. Politehnica Publishing, Timisoara, 2006

5. KHEDKAR, S.B., THAKRE, R.D., MAHANTARE, Y.V., RAVI GONDNE, Study of Implementing $5 S$ Techniques in Plastic Moulding Industry, International J ournal of Modern Engineering Research (IJMER), 2, Issue.5, 2012 p. 3653-3656

6. ASHISH MISHRA, PANKAJ MISHRA AND SACHENDRA, Six Sigma Methodology In A Plastic Injection Molding Industry: A Case Study, International J ournal of Industrial Engineering and Technology, 7, No 1, 2015, p. 15-30

7. IGNELL, S., PORSGAARD, P., RIGDAHL, M., Ghost marksuglossrelated defects in injection-molded plastics, Polymer engineering and science, 52, Issue: 2, 2012, p. 459-466

8. ZHANG, Y., DENG, Y., Minimization of Surface Sink Defect of Injection Molded Plastic Part Based on Kriging Surrogate Modeling, 5th ChinaJapan Conference on Mechatronics, Japan, Chem Ind Press, 2008, p. 37-40

9.CHEN, WC.,KURNIAWAN, D., Process Parameters Optimization for Multiple Quality Characteristics in Plastic Injection Molding using Taguchi Method, BPNN, GA, and Hybrid PSO-GA, International J ournal of Precision Engineering and Manufacturing, 15, Issue: 8, 2014, p. 1583-1593

10.LATIF, L., SAIDPOUR, H., Assessment of plastic mixture quality in injection moulding process, Polymer Testing, 16, Issue: 3, 1997, p. 241-258, DOI: 10.1016/S0142-9418(96)00045-1

11.LAI, H.E., WANG, P. ., Study of process parameters on optical qualities for injection- molded plastic lenses, Applied Optics, 47, Issue: 12, 2008, p. 2017-2027, DOI: 10.1364/A0.47.002017

12.MASUDA, N., YOKOI, H., Experimental Analysis of Generation Process of White Tree-ring-like Surface Defects in Injection Molding, Proceedings of the Regional Conference Graz 2015 - Polymer Processing Society PPS, Book Series: AIP Conference Proceedings, 1779, 2016, DOI: 10.1063/1.4965455

13.SANNEN, S., DE KEYZER, J ., VAN PUYVELDE, P., The Influence of Melt and Process Parameters on the Quality and Occurrence of Part Defects in Water-assisted Injection Molded Tubes, International Polymer Processing, 26, Issue: 5, 2011, p. 551-559, DOI: 10.3139/ 217.2490

14. JIANG, S., SU, M., LI, J., ET AL., The Inherent Defects of Injection Molding Products and its Special Processes, International Conference on Information Engineering for Mechanics and Materials (ICIMM 2011), Shanghai, Book Series:Applied Mechanics and Materials, 8081,2011, p. 385-390 
15. PASARE, M, On the mitigation actions of defects for plastical deformed parts, Fiability and Durability Issue: 2, Academica Brancusi, Targu Jiu, 2016, p.92-95

16. ZHENG, ZS., QU, XH., LEI, CM., Defects and variation of viscosity in powder injection molding filling process, Acta Metallurgica Sinica, 43, Issue: 2, 2007, p. 187-193

17.LI, Q., GUO, Y.L., HOU, J.L., ZHU, W.J ., The M-Integral based failure description on elasto-plastic materials with defects under biaxial loading, Mechanics of Materials, 112, 2017, p. 163-171 DOI: 10.1016/ j.mechmat.2017.06.004

18. CLEJA-TIGOIU, S., TIGOIU, V., Modeling anisotropic damage in elasto-plastic materials with structural defects, 12th International Conference on Computational Plasticity (COMPLAS) Barcelona, 2013, Computational Plasticity XII: Fundamentals and Applications, 2013, p. 453-463

19. ISHIKAWA, K., LOFTUS, JH., Introduction to quality control Tokyo, Japan: 3A Corporation, 1990

20. CHOKKALINGAM, B., RAJA, V., ANBURAJ, J., et al., Investigation of Shrinkage Defect in Castings by Quantitative Ishikawa Diagram, Archives of Foundry Engineering, 17, Issue: 1, 2017, p. 174-178 21. SALVADOR, CG., GOLDFARB, N.,Ishikawa cause and effect diagrams: A useful tool in designing economic analyses, Value in Health, 7, Issue: 3, 2004, p. 301-302
22. LUCA, L., CIRTINA, L.M., STANCIOIU, A., Study on Identification and Classification of Causes which Generate Welds Defects. Applied Mechanics and Materials Vol. 657, 2014, p. 256-260, Trans Tech Publications, Switzerland, doi:10.4028/www.scientific.net/AMM.657.256 23. LUCA, L., A new model of Ishikawa diagram for quality assessment, 20th Innovative Manufacturing Engineering and Energy Conference (IManEE 2016), Greece, Date: SEP 23-25, 2016, Book Series: IOP Conference Series-Materials Science and Engineering, 161, 2016, Article Number:UNSP 012099

24. LUCA, L., FILIP, C.P.,On the assessment of the public order services quality by using classic instruments of quality management, 17th International Conference the Knowledge-Based Organization, Sibiu, Conference Proceedings 1: Management and Military Sciences, Book Series: Knowledge Based Organization International Conference, 2011, p. 691-696

25. CIRTINA, L.M., CIRTINA, D., LUCA L., Quality Management in Projects - Quality Planning, Applied Mechanics and Materials, 657, 2014 p. 891-895, available www.scientific.net, Trans Tech Publications, Switzerland

26. DALE, B. G., Managing quality (2-nd Ed.), Prentice Hall, Horls, 1994

Manuscript received: 15.12 .2019 